\title{
ASSESSM ENT OF REFERENCE VALUES OF CHEST EXPANSION AMONG HEALTHY ADULTS IN PUNE, INDIA
}

\section{Rajani S. Pagare *1, Ratnaprabha B. Pedhambkar ${ }^{2}$.}

${ }^{* 1}$ Associate Professor (Cardio-Respiratory Physiotherapy), Deccan Education Society's Brijlala Jindal College Of Physiotherapy, Fergusson Campus, Shivaji nagar, Pune 41105, M aharashtra, India.

${ }^{2}$ Associate Professor (Community Medicine), SM BT Institute Of Medical Sciences and Research Center, Dhamangaon, Nashik, M aharashtra, India.

\section{ABSTRACT}

Background: Chest expansion measurements are used to evaluate the patient's baseline status, treatment effectiveness, and progression of respiratory diseases with regards to chest wall mobility and respiratory muscle function. It is important to know the reference values of chest expansion of healthy adult Indian population for precise interpretation.

Aim: To determine reference values of chest expansion for healthy adult Indian population.

Methodology: Total 576 healthy adults participated in this observational study which was carried out at teaching institute and community in Pune city, India. Participants were apparently healthy and non smoking individuals who are recruited by purposive sampling technique. Data was obtained by measuring chest expansion with participants in standing position, elbows slightly flexed so that the hands rested on hips. Chest was exposed and with the help of an non stretchable inch tape the chest expansion was measured at three levels that is $2^{\text {nd }}$ intercostal space(ICS), $4^{\text {th }}$ intercostal space, and zyphoid process.

Statistical Analysis: Data was analyzed with descriptive and inferential statistics. Level of significance was set at $0.05 \alpha$-level.

Results: 576 Participants were recruited for the study.293 were females and 283 were males. The mean age of female participants was 38.43 years (SD=16.52 years), and the mean age of males were 39.99 years ( $S D=17.13$ years). Results showed that in female participants mean expansion at $2^{\text {nd }}$ ICS was 2.22 inches (SD $=0.76$ inches), at $4^{\text {th }}$ ICS was 2.22 inches (SD=0.73 inches) and at zyphoid process level was 2.27 inches (SD $=0.78$ inches) while in male participants mean expansion at $2^{\text {nd }}$ ICS was 2.76 inches (SD $=0.90$ inches), at $4^{\text {th }}$ ICS was 2.71 inches $(S D=0.82$ inches) and at zyphoid process level was 2.99 inches ( $S D=0.87$ inches). Chest expansion in male participants' at all three levels was significantly higher than female participants. There was statistically significant difference between chest expansion at $2^{\text {nd }}, 4^{\text {th }}$ ICS and zyphoid process level in males but there was no such difference found in females. It was also observed that there was age-wise reduction in chest expansion in both males and females.

Conclusion: It was concluded that male chest expansion was significantly higher than female participants. Study has provided the preliminary baseline for the chest expansion measurements obtained from healthy adult Indian population.

KEY WORDS: Chest Expansion, Reference Values, Healthy, Indian Population.

Address for correspondence: Dr. Rajani S Pagare (PT), Associate Professor (Cardio-Respiratory Physiotherapy), Deccan Education Society's Brijlala Jindal College Of Physiotherapy, Fergusson Campus, Shivaji nagar, Pune 41105, Maharashtra, India. E-Mail: pagare_rs@yahoo.com

\section{Access this Article online}

Quick Response code

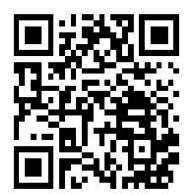

DOI: 10.16965/ijpr.2016.197
International Journal of Physiotherapy and Research

ISSN 2321- 1822

www.ijmhr.org/ ijpr.html

Received: 22-11-2016 Accepted: 20-12-2016

Peer Review: 22-11-2016 Published (0): 11-02-2017

Revised: None
Published (P): 11-02-2017 


\section{INTRODUCTION}

There are various clinical techniques to know the status of the respiratory system of the patient. Normal chest wall mobility is important for effective lung expansion and subsequent ventilation. Respiratory evaluation is an integral part of Chest Physiotherapy. Respiratory evaluation involves taking a detailed history of the patient and several examinations done by inspection, palpation, percussion as well as auscultation. Examination of the chest movement is also an important tool for respiratory system evaluation of the patient. Thoracic movements can be checked by observatory, palpatory and by using an inch tape [1].

The movement of thoracic rib cage is attributed to the lung expansion and the movement of the rib cage. Pathologic changes in the lungs or thoracic cage can restrict the thoracic movement. Reversal of disease condition by medical, surgical and physiotherapeutics can improve the thoracic expansion. Therefore measurement of thoracic expansion with an inch tape becomes a reliable objective outcome measure in patients having respiratory diseases [2]. The evaluation technique in many of the literature review have used palpatory method to measure the chest expansion at the lower chest level or by using measure tape only at the $6^{\text {th }}$ rib level [3]. A difference of more than $5 \mathrm{~cm}$ between full expiration and full inspiration is regarded as normal [1]. The palpatory method is subjective, therefore cannot be counted as a standardized method of evaluation. M ovements of the ribs occur at the costotransverse and the costovertebral joints. The orientation of these joints varies in the upper and lower ribs. Due to this pump handle movement is seen in upper ribs where as bucket handle movement is seen in lower ribs. Therefore both the upper, middle and lower chest movement should be assessed [4]. Chest expansion measurements in subjects without impairment are prerequisite to normative data collection and subsequent comparison of values obtained from patient with impairments in chest wall mobility. Very little is known about the chest expansion at these different levels. Also reference values are not available for the Indian population. This study was carried out with an aim to determine chest expansion measurement at different levels in an adult population of Pune city, India.

\section{MATERIALS AND METHODS}

This observational study was conducted at reputed Physiotherapy Teaching Institute and Community in Pune city of $M$ aharashtra state in India. This study was conducted between August 2015 to December 2015.

Study subjects: 576 Medically fit healthy individuals of 18 years and above of both genders who had given written informed consent were included in the study by purposive sampling technique. Individuals with history of diagnosed pulmonary disease or history of injury, trauma or surgery in the chest area or with history of smoking as well as those who have not given written informed consent were excluded from the study.

Study protocol: Study was carried out with study subjects in standing position, elbows slightly flexed so that the hands rested on hips. Chest was exposed and with the help of non stretchable inch tape the chest expansion was measured at three levels that is $2^{\text {nd }}$ Intercostal Space, $4^{\text {th }}$ Intercostal Space and Zyphoid process. Subject was asked to exhale the air as much as possible and then take a maximal deep inspiration. The difference between the full expiration and full inspiration was noted. Three trails were given at each level and average of three readings was noted.

Statistical Analysis: Data was analysed by using Primer of Biostatistics [5]. For descriptive statistics mean, standard deviation, proportions and percentages were used. For inferential statistics student " $\mathrm{t}$ " test and Analysis of Variance (ANOVA) were used. Statistical significance was taken as $<0.05$.

Ethical aspects: The study was conducted according to the guidelines of the Helsinki Declaration and of Good Clinical Research Practice. The research study was approved by an institutional ethical committee. All the study participants were told about the nature and outcome of study and written informed consent was taken.

\section{RESULT}

Total 576 subjects were included in the study. 
Table 1: Gender Wise M ean Chest Expansion of the Study Subjects.

\begin{tabular}{|c|c|c|c|c|c|}
\hline \multirow{2}{*}{ Sr. No. } & \multirow{2}{*}{ Level } & \multicolumn{2}{|c|}{ Females (n=293) } & \multicolumn{2}{c|}{ Males (n=283) } \\
\cline { 3 - 6 } & & $\begin{array}{c}\text { Mean } \\
\text { (in Inches) }\end{array}$ & $\begin{array}{c}\text { Std. Dev. (in } \\
\text { Inches) }\end{array}$ & $\begin{array}{c}\text { Mean } \\
\text { (in Inches) }\end{array}$ & $\begin{array}{c}\text { Std. Dev } \\
\text { (in Inches) }\end{array}$ \\
\hline $\mathbf{1}$ & $\mathbf{2}^{\text {nd }}$ ICS & 2.22 & 0.76 & 2.76 & 0.9 \\
\hline $\mathbf{2}$ & $\mathbf{4}^{\text {th }}$ ICS & 2.22 & 0.73 & 2.71 & 0.83 \\
\hline 3 & Zyphoid Process & 2.27 & 0.78 & 2.99 & 0.87 \\
\hline
\end{tabular}

Table 2: Gender-wise comparison of Chest Expansion at various levels.

\begin{tabular}{|c|c|c|c|c|c|c|c|}
\hline \multirow[b]{2}{*}{ Sr. No. } & \multirow[b]{2}{*}{ Level } & \multicolumn{2}{|c|}{ Females ( $n=293$ ) } & \multicolumn{2}{|c|}{ Males ( $n=283$ ) } & \multirow[b]{2}{*}{ "t"value } & \multirow[b]{2}{*}{ "p" Value } \\
\hline & & $\begin{array}{c}\text { Mean } \\
\text { (in Inches) }\end{array}$ & $\begin{array}{l}\text { Std. Dev, } \\
\text { (in Inches) }\end{array}$ & $\begin{array}{l}\text { Mean } \\
\text { (in Inches) }\end{array}$ & $\begin{array}{l}\text { Std. Dev } \\
\text { (in Inches) }\end{array}$ & & \\
\hline 1 & $2^{\text {nd }}$ ICS & 2.222 & 0.76 & 2.76 & 0.9 & 7.79 & 0.001; HS* \\
\hline 2 & $4^{\text {th }}$ ICS & 2.22 & 0.73 & 2.71 & 0.83 & 7.6 & $0.001 ; \mathrm{HS}^{*}$ \\
\hline 3 & $\begin{array}{l}\text { Zyphoid } \\
\text { Process }\end{array}$ & 2.278 & 0.78 & 2.99 & 0.87 & 10.44 & $0.001 ; H S^{*}$ \\
\hline
\end{tabular}

*HS= Highly Significant

Table 3: Age wise comparison of Chest Expansion at various levels in Males $(n=283)$.

\begin{tabular}{|c|c|c|c|c|c|c|}
\hline Sr. No. & $\begin{array}{l}\text { Level of } \\
\text { Expansion }\end{array}$ & $\begin{array}{c}\text { Age Group (in } \\
\text { Years) }\end{array}$ & $\begin{array}{c}\text { Mean } \\
\text { (in Inches) }\end{array}$ & $\begin{array}{l}\text { Std. Dev. } \\
\text { (in Inches) }\end{array}$ & F value & $p$ value \\
\hline \multirow{6}{*}{1} & \multirow{6}{*}{$2^{\text {nd }}$ ICS } & $18-24$ & 3.18 & 0.78 & \multirow{6}{*}{12.28} & \multirow{6}{*}{$0.001 ; \mathrm{HS}$} \\
\hline & & $25-34$ & 2.98 & 0.81 & & \\
\hline & & $35-44$ & 2.9 & 0.67 & & \\
\hline & & $45-54$ & 2.68 & 0.93 & & \\
\hline & & $55-64$ & 2.19 & 0.85 & & \\
\hline & & 65 and above & 2.13 & 0.84 & & \\
\hline \multirow{6}{*}{2} & \multirow{6}{*}{$4^{\text {th }}$ ICS } & $18-24$ & 3.12 & 0.66 & \multirow{6}{*}{15.51} & \multirow{6}{*}{$0.001 ; \mathrm{HS}$} \\
\hline & & $25-34$ & 2.93 & 0.7 & & \\
\hline & & $35-44$ & 3.01 & 0.7 & & \\
\hline & & $45-54$ & 2.51 & 0.75 & & \\
\hline & & $55-64$ & 2.2 & 0.78 & & \\
\hline & & 65 and above & 2.09 & 0.76 & & \\
\hline \multirow{6}{*}{3} & \multirow{6}{*}{$\begin{array}{l}\text { Zyphoid } \\
\text { Process }\end{array}$} & $18-24$ & 3.15 & 0.71 & \multirow{6}{*}{5.71} & \multirow{6}{*}{$0.001 ; \mathrm{HS}$} \\
\hline & & $25-34$ & 3.23 & 0.83 & & \\
\hline & & $35-44$ & 3.33 & 0.66 & & \\
\hline & & $45-54$ & 2.86 & 0.96 & & \\
\hline & & $55-64$ & 2.63 & 0.85 & & \\
\hline & & 65 and above & 2.59 & 1.98 & & \\
\hline
\end{tabular}

Out of which 293 (50.86\%) were females and $283(49.13 \%)$ were males. The mean age of female participants was 38.43 years $(S D=16.52$ ), and the mean age of males were 39.99 years $(\mathrm{SD}=17.13)$.

M ean chest expansion of females at $2^{\text {nd }}$ ICS was 2.22 inches (SD $=0.76)$, at $4^{\text {th }}$ ICS was 2.22 inches $(\mathrm{SD}=0.73)$ at Zyphoid process level was 2.27 inches $(S D=0.78)$. There was no statistically significant difference observed in chest expansion at various levels in females ( $F$ value $=1.03$; $p=0.356$; not significant).

M ean chest expansion of males at $2^{\text {nd }}$ ICS was
2.76 inches (SD $=0.90)$, at $4^{\text {th }}$ ICS was 2.71 inches $(\mathrm{SD}=0.82)$ at at Zyphoid process level was 2.99 inches $(S D=0.87)$. There was statistically significant difference observed in chest expansion at various levels in males (F value $=17.96 ; p=0.001$; highly significant).

In Table no.3 and 4, It was observed that there was statistically significant age-wise difference in chest expansion values at all three levels of measurement in both male and female subjects.

Table 4: Age wise Comparison of Chest Expansion at various levels in Females $(n=293)$.

\begin{tabular}{|c|c|c|c|c|c|c|}
\hline Sr. No. & \begin{tabular}{|c|} 
Level of \\
Expansion
\end{tabular} & $\begin{array}{l}\text { Age Group } \\
\text { (in Years) }\end{array}$ & $\begin{array}{c}\text { Mean } \\
\text { (in Inches) }\end{array}$ & $\begin{array}{c}\text { Std. Dev. } \\
\text { (in Inches) }\end{array}$ & F value & $p$ value \\
\hline \multirow{6}{*}{1} & \multirow{6}{*}{$2^{\text {nd }}$ ICS } & $18-24$ & 2.72 & 0.71 & \multirow{6}{*}{19.78} & \multirow{6}{*}{$0.001 ; H S^{*}$} \\
\hline & & $25-34$ & 2.38 & 0.64 & & \\
\hline & & $35-44$ & 1.95 & 0.69 & & \\
\hline & & $45-54$ & 2.01 & 0.66 & & \\
\hline & & $55-64$ & 1.75 & 0.67 & & \\
\hline & & 65 and above & 1.69 & 0.56 & & \\
\hline \multirow{6}{*}{2} & \multirow{6}{*}{$4^{\text {th }}$ ICS } & $18-24$ & 2.61 & 0.7 & \multirow{6}{*}{10.48} & \multirow{6}{*}{$0.001 ; \mathrm{HS}^{*}$} \\
\hline & & $25-34$ & 2.32 & 0.58 & & \\
\hline & & $35-44$ & 1.93 & 0.66 & & \\
\hline & & $45-54$ & 1.95 & 0.54 & & \\
\hline & & $55-64$ & 1.88 & 0.88 & & \\
\hline & & 65 and above & 2.13 & 0.8 & & \\
\hline \multirow{6}{*}{3} & \multirow{6}{*}{$\begin{array}{l}\text { Zyphoid } \\
\text { Process }\end{array}$} & $18-24$ & 2.41 & 0.69 & \multirow{6}{*}{2.62} & \multirow{6}{*}{$0.02 ; \mathrm{HS}^{*}$} \\
\hline & & $25-34$ & 2.46 & 0.83 & & \\
\hline & & $35-44$ & 2.27 & 0.78 & & \\
\hline & & $45-54$ & 2.17 & 0.73 & & \\
\hline & & $55-64$ & 2.05 & 0.88 & & \\
\hline & & 65 and above & 2.01 & 0.81 & & \\
\hline
\end{tabular}

*HS=Highly Significant

\section{DISCUSSION}

Chest expansion measurement is an important assessment in physical examination of Cardio- Respiratory patients. Chest wall excursion measurements give us a measure of chest wall mobility. Measurement of the chest expansion can be done by inspection and palpation method or can be assessed objectively by non stretchable inch tape. It is recommended that the placement of the measuring tape should be at the lower rib level. There are two movements of the thoracic cage. The upper chest movement is described as pump handle movement known to increase the antero-posterior diameter of the chest where as lower chest movement is called as Bucket handle movement known to increase the transverse diameter of the thorax [4]. The difference in the movement 
is because of the orientation of costovertebral and costotransverse joint. Hence the tape was placed at the three levels to find any differences between them. Soft tissue landmark was avoided because it varies with the individual. Also females have predominantly thoraco-abdominal breathing where as males has abdomino-thoracic breathing [5].

This study was carried out to determine reference values of chest expansion for healthy adult Indian population. In the present study mean chest expansion of females at $2^{\text {nd }}$ ICS was 2.22 inches (SD $=0.76)$, at $4^{\text {th }}$ ICS was 2.22 inches $(\mathrm{SD}=0.73)$ at Zyphoid process was 2.27 inches $(S D=0.78)$. Mean chest expansion of males at $2^{\text {nd }}$ ICS was 2.76 inches (SD $=0.90$ ), at $4^{\text {th }}$ ICS was 2.71 inches $(S D=0.82)$ at Zyphoid process was 2.99 inches $(S D=0.82)$. Indian has higher Chest expansion measurement as compared to the Nigerian population [6]. Their study also shows lesser values of Chest expansion in females as compared to males.

However compared to the western population Indians have lesser Chest expansion values [7]. In our study there was age wise difference in the chest expansion both in males and females. In younger age groups mean chest expansion was higher compared to older age groups. Similar finding was observed by Adedoyin et al in the study conducted amongst Nigerian Population as well as study conducted by Moll and Wright in western population [8,9]. It is also seen that the chest expansion declines with the age. This can be attributed to the aging process $[10,11]$. Calcification of the costochondral cartilage and loss of elasticity of the connective tissue reduces the compliance of the thoracic cage. Reduction of lung compliance due to aging reduces chest expansion [12].

In the present study, chest expansion in male participants at all three levels was significantly higher than female participants. The lung volumes and capacities vary with the age, height, body surface area. Females have lesser average height and the body surface area than the males also the force generated by the Inspiratory muscles of males is greater than the females [12]. The difference in the chest expansion measurements can also be due to variable instructions given by the tester [12].
The expansion at all the three levels in females is same whereas significant difference is seen in males.

\section{CONCLUSION}

The present study has given reference values of chest expansion at $2^{\text {nd }} I C S, 4^{\text {th }}$ ICS and at Zyphoid process level amongst the healthy adults especially in urban population of Pune city which is located in western part of India. Normative Values of Chest expansion measurement in males and females of various age group is established. Males have greater expansion than females. Age wise there is difference in the chest expansion in both males and females. This study is empirical one and similar types of multi-centric studies are recommended as India is large country with lots of diversity in all respects in different regions. Whereas limitation of the present study is that it was carried out at only one centre, further extensive studies required in the same.

\section{ACKNOW LEDGEM ENTS}

I sincerely Thank the head of the Institution for granting me permission to conduct the study in the College .I also thank the Staffs and Students of the colleges of DE society. We also Thank Dr.Harshal Pandve for guiding us through the statistical analysis and interpretation of the data.

\section{Conflicts of interest: None}

\section{REFERENCES}

[1]. Macleod's clinical examination, edited by Graham Douglas, Fiona Nicol and Colin Robertson. 12th ed. Philadelphia: Churchill Livingstone, 2009, Pg. No.170.

[2]. Bockenhuer SE, Chen H, Julliard KN, Weedon J. M easuring Thoracic Excursion, Reliability of cloth tape measure technique. J Am Osteopathic Assoc. 2007;107:191-6.

[3]. Egan's Fundamentals of Respiratory care, edited by Robert L Wilkins, J.K. Stoller, 9th Ed, M osby 2009, Pg. No. 334.

[4]. Kapandji IA. The Physiology of the Joints Vol \#3. Edinburgh: Churchill Livingstone, 1978, Pg.No. 1381.

[5]. Stanton Glantz SA. Primer of Biostatistics. $6^{\text {th }}$ Ed. New York. McGraw-Hill; 2005

[6]. Adedoyin RA, , Adeleke OE, , Fehintola AO, , Erhabor GE, , Bisiriyu LA, . Reference Values for Chest Expansion among Adult Residents in Ile-Ife, Nigeria- a Cross-Sectional Study. J Phys Ther. 2013;6(2):54-58. 
[7]. Moll JMH, Wright V. An objective clinical study of chest expansion. Ann.Rheum.Dis1972;31:1-8.

[8]. Ruivo S, Viana P, Beta C, Effects of aging on lung function. A comparison of lung function in healthy adults and the elderly .Rev port Pneumol.2009 julAug;15(4):629-53.

[9]. Barrie Pickles, Ann Compton et al. Physiotherapy with older people published by W B Saunders company Itd. Pg 78-79. 2003 edition.

[10]. Needham CD, Rogan M C, M CDonald I. Normal standards for lung volumes, intrapulmonary gas-mixing, and maximum breathing capacity. Thorax. 1954;9:313-325.
[11]. Fagevik Olsen MF, Lindstrand H, Broberg JL, Dhal EW. M easuring Chest expansion; A study comparing two different instructions. Advances in Physiotherapy,2011;13:94-98.

[12]. Ragnarsdottir M , Kristinsdottir E K. Breathing movements and breathing patterns among healthy men and women 20-69 years of age. Respiration 2006;73:48-54.

How to cite this article:

Rajani S. Pagare, Ratnaprabha B. Pedhambkar. ASSESSM ENT OF REFERENCE VALUES OF CHEST EXPANSION AM ONG HEALTHY ADULTS IN PUNE, INDIA. Int J Physiother Res 2017;5(1):1819-1823. DOI: 10.16965/ijpr.2016.197 